\title{
Prevalence of anemia among medical students of nobel medical college and correlation with body mass index
}

\author{
Renu Yadav 1 , Nisha Ghimire ${ }^{2}$, Soumitra Mukhopadhyay ${ }^{3}$, Subodh Kumar Yadav ${ }^{4}$ \\ ${ }_{1,2,3}$ Assistant Professor, Department of Physiology, Nobel Medical College \& Teaching Hospital, Biratnagar, Nepal, \\ ${ }^{4}$ Assistant Professor, Department of Anatomy, Nobel Medical College \& Teaching Hospital, Biratnagar, Nepal
}

Background: Studies have concluded that the medical students of hostels are at high risk of anemia due to inappropriate diet and their long schedules that indirectly affect their performance. Thus, concerning for the long duration of medical studies, it has become a serious medical issue. Aims and Objective: Thus, our objective is to determine the prevalence of anemia among medical students in Nobel Medical College and Teaching Hospital, Nepal. Materials and Methods: This is a descriptive cross-sectional study which was conducted and Teaching Hospital from January 2017 to December 2017 where all the subjects were selected with convenient sampling technique. The total of 150 MBBS students (male $=95$, female $=55$ ), age 18-25 years were included in the study who were clinically healthy. The demographic data (name, age, sex, address) and anthropometric variables (height, weight, body mass index) were recorded and hemoglobin was estimated by Sahli's acid hematin method. Results: Only $42.1 \%$ of total were mild anemic and $11.6 \%$ were moderately anemic. Among female, $1.8 \%$ were severely anemic, $9.1 \%$ were moderately anemic and $41.8 \%$ were mild anemic. Compared to male, anemia in female medical students was found to be more extensive. Conclusions: It has been concluded from the above study that the mild anemia is highly prevalent among medical students regardless of gender. Though the subjects are not severely affected, it is a concerned issue since the cause might be inappropriate food habit or the food facilities available at hostels.

Key words: Anthropometric variables; body mass index; Sahli's acid hematin
Access this article online

\section{Website:}

http://nepjol.info/index.php/AJMS

DOI: 10.3126/ajms.v11i3.27124

E-ISSN: 2091-0576

P-ISSN: 2467-9100

Copyright (c) 2020 Asian Journal of Medical Sciences

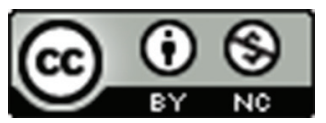

This work is licensed under a Creative Commons Attribution-NonCommercial 4.0 International License.

\section{INTRODUCTION}

Anemia, deficiency of hemoglobin $(\mathrm{Hb})$, is a condition which is globally concern since World Health Organization (WHO) estimates 293 million young children and 468 million non-pregnant women to be anemic. Among which $50 \%$ are due to iron deficiency (ID).The causative factors for iron deficiency anemia are; inadequate intake of iron, infection, blood loss and impairment of mucosal absorption of iron..$^{1-3}$ Iron deficiency anemia affects the development of a country by decreasing the cognitive development of children and the productivity of adults. ${ }^{4} \mathrm{It}$ also adversely affects reproductive life leading to increased infant and maternal mortality. ${ }^{5-7}$
The prevalence of anemia in women is around $21-80 \%$ worldwide which is greater than men. ${ }^{1,8}$ Improper food habit, stress and busy schedule has a great impact on inadequate nutrition. Evidence suggested that the medical students staying in hostels are at high risk of anemia because of long college schedule, clinical postings, stress and inappropriate diet in their hostel. ${ }^{9}$ Female of developing countries are at high risk of iron deficiency. ${ }^{10}$ Thus, the etiological factors concluded to be age, sex, social class, dietary deficiencies, stress, menstrual blood loss and helminthic infection. ${ }^{11,12}$

Thus, anemia is a major public health problem being highest prevalence among children aged $<5$ years and pregnant 
women. ${ }^{13}$ Anemia is considered severe, $\mathrm{Hb}<7 \mathrm{~g} / \mathrm{dl}$, moderate, $\mathrm{Hb}=7-9.9 \mathrm{~g} / \mathrm{dl}$, and mild, $\mathrm{Hb}=10-11 \mathrm{~g} / \mathrm{dl} .{ }^{14}$ The objective of our study is to estimate the anemia prevalence of medical students from Nobel Medical College, Biratnagar.

\section{MATERIALS AND METHODS}

This study was conducted in Physiology lab of Nobel Medical College and Teaching Hospital from January 2017 to December 2017. All the first-year medical students including both male and female were taken as study group. The total of 150 MBBS students (male=95, female=55), age 18-25 years were included in the study. This is a descriptive cross-sectional study where all the subjects selected with convenient sampling technique who were clinically healthy. The Institutional Review Board of Nobel Medical College and Teaching Hospital has approved the research protocol.

The students willing to give informed written consent were included in the study. A questionnaire was prepared related to menstruation, duration of bleeding period, menstrual cycle, known hemoglobinopathies and worm infestation. Subjects with cardiovascular illness, renal disease, diabetes, obstructive or restrictive lung disease and other chronic illness were excluded from the study.

A well designed proforma was prepared and recording of each subject with demographic data (name, age, sex, address) and anthropometric variables like height, weight, body mass index (BMI) were recorded in the physiology laboratory during morning time, 9 am to 12 noon. The age of the selected subjects for male was 19.96 2.24 (mean $\pm \mathrm{SD}$ ) years and the female subjects was 19.45 \pm 0.91 (mean $\pm \mathrm{SD}$ ). Height and weight were measured by stadiometer and BMI was calculated by Quetelet's index: $\mathrm{BMI}=$ weight in $\mathrm{kg} /$ height in $\mathrm{m}^{2}$. International obesity task force (IOTF-2000) has proposed the standards for adult's obesity in Asia: A minimum cut off point of $18.5 \mathrm{~kg} / \mathrm{m}^{2}$ is defined as acutely under nutrition and a BMI of $23 \mathrm{~kg} /$ $\mathrm{m}^{2}$ indicates over nutrition. A BMI of more than $25 \mathrm{~kg} /$ $\mathrm{m}^{2}$ refers to obesity. ${ }^{15}$

Hemoglobin level was estimated by Sahli's acid hematin method. The hemoglobin tube was filled with $\mathrm{N} / 10$ hydrochloric acid up to 2 grams $\%$. Then the graduated hemoglobin tube was placed in the slot of comparator box (hemoglobinometer) kept on the table. Capillary blood was collected by the finger prick (lancet) method and blood was drawn into hemoglobin pipette up to $20 \mu \mathrm{l}$ marking. Then, the blood from the hemoglobin pipette was mixed with hydrochloric acid in hemoglobin tube by glass stirrer.
The solution in the tube was left as it is for 5 minutes to form acid hematin. The acid hematin was diluted by adding distilled water gradually with the dropper till it matched with the standard brown tinted glass plates of the comparator box. Results were noted as gram/dl.

Statistical package for social science (SPSS) version 25.0 was used to analyze the data. Descriptive and frequency statistics were used to show the demographic characteristics of the anemia, age, height, weight and BMI. Cross tabulations were used to see the association between different parameters.

\section{RESULTS}

Total 150 first year medical students were enrolled in the study. Among total participants, 95 were male and 55 were female. The descriptive statistics of $\mathrm{Hb}$ concentration along with age, height (ht), weight (wt) and BMI of male and female participants are tabulated in table 1 and table 2 respectively. Correlation of BMI with hemoglobin was recorded for male and female. (Table 3)

Table 1 shows the mean age of male participants $19.96 \pm 2.22$ years, mean ht $161.69 \pm 6.19 \mathrm{~cm}$, mean wt $56.41 \pm 5.36 \mathrm{~kg}$, mean BMI $21.75 \pm 1.81 \mathrm{~kg} / \mathrm{m}^{2}$, mean Hb $11.18 \pm 1.48 \mathrm{gm} / \mathrm{dl}$.

Table 2 shows the age of male participants $19.45 \pm 0.919$ years, mean ht $154.05 \pm 5.18 \mathrm{~cm}$, mean wt

\begin{tabular}{|c|c|c|c|c|}
\hline Variables & Minimum & Maximum & Mean & SD \\
\hline Age (years) & 18 & 27 & 19.96 & 2.22 \\
\hline height $(\mathrm{cm})$ & 150 & 177 & 161.69 & 6.19 \\
\hline Weight (kg) & 44 & 68 & 56.41 & 5.36 \\
\hline BMI $\left(\mathrm{kg} / \mathrm{m}^{2}\right)$ & 17.84 & 25.46 & 21.75 & 1.81 \\
\hline $\mathrm{Hb}(\mathrm{gm} / \mathrm{dl})$ & 8.20 & 15.60 & 11.18 & 1.48 \\
\hline
\end{tabular}

\begin{tabular}{|c|c|c|c|c|}
\hline Variables & Minimum & Maximum & Mean & SD \\
\hline Age (years) & 18 & 21 & 19.45 & 0.919 \\
\hline height $(\mathrm{cm})$ & 142 & 162 & 154.05 & 5.18 \\
\hline weight (kg) & 48 & 58 & 51.80 & 2.39 \\
\hline BMI $\left(\mathrm{kg} / \mathrm{m}^{2}\right)$ & 17.28 & 26.30 & 21.13 & 2.04 \\
\hline $\mathrm{Hb}(\mathrm{gm} / \mathrm{dl})$ & 6.00 & 14.00 & 11.08 & 1.43 \\
\hline
\end{tabular}

\begin{tabular}{|c|c|c|}
\hline Variables & Pearson correlation & Sig. (2-tailed) \\
\hline $\begin{array}{l}\mathrm{BMI}\left(\mathrm{kg} / \mathrm{m}^{2}\right) \\
\mathrm{Hb}(\mathrm{gm} / \mathrm{dl})\end{array}$ & -0.112 & 0.171 \\
\hline
\end{tabular}


$51.80 \pm 2.39 \mathrm{~kg}$, mean BMI $21.13 \pm 2.04 \mathrm{~kg} / \mathrm{m}^{2}$, mean $\mathrm{Hb}$ $11.08 \pm 1.43 \mathrm{gm} / \mathrm{dl}$.

Hemoglobin concentration of total medical students to body mass index was found to be inversely correlated which non-significant.

In present study, all the male and female participants were categorized into different group as Group-1, 2, 3 and 4 based on the concentration of hemoglobin according to WHO criteria.

Group 1; Normal $=>11 \mathrm{~g} / \mathrm{dl}$

Group 2; mild $=10-11 \mathrm{~g} / \mathrm{dl}$,

Group 3; moderate $=7$ to $9.9 \mathrm{~g} / \mathrm{dl}$

Group 4; Severe anemia $=<7 \mathrm{~g} / \mathrm{dl}$

Figure 1 shows the percentage frequency analysis of anemia for male for different group (Group 1, 2, 3, 4). About $46 \%$ of male were found to be normal. Only $42.1 \%$ of total were mild anemic and $11.6 \%$ were moderately anemic. None of the male students were found to be severely anemic.

Among female, 1.8\% were severely anemic, 9.1\% were moderately anemic and $41.8 \%$ were mild anemic. Thus figure 2 concludes that though the percentage of anemia was less in female compared to male, anemia was quite extensive among female.

\section{DISCUSSION}

Anemia, a subject of public health concern, is the most common form of condition caused by malnutrition. Various researches documented a large prevalence of anemia due to nutritionally inadequate diet among medical students. Present study is conducted to assess the prevalence and severity of anemia among medical students of Nobel Medical College and teaching hospital, Biratnagar.

Total of 150 first year medical students were enrolled in the study including both male and female. Among participants, 95 were male and 55 were female. The mean age of male participants were $19.96 \pm 2.26$ and the female participants were $19.45 \pm 0.919$.

In present study, the minimum recorded concentration of hemoglobin among male participants was $8.20 \mathrm{gm} / \mathrm{dl}$ and maximumwas $15.60 \mathrm{gm} / \mathrm{dl}$. Similarly, the minimum and maximum value recorded was $6 \mathrm{gm} / \mathrm{dl}$ and $14 \mathrm{gm} / \mathrm{dl}$ respectively. The mean $\mathrm{Hb}$ was $11.18 \mathrm{gm} / \mathrm{dl}$ and $11.08 \mathrm{gm} / \mathrm{dl}$ for male and female respectively. Out of 95 male students $42.1 \%$ were recorded as mildly anemic and $11.6 \%$ were moderately anemic. Among 55 female participants 41.8 $\%$ were mild anemic, $9.1 \%$ were moderately anemic and $1.8 \%$ were severely anemic.

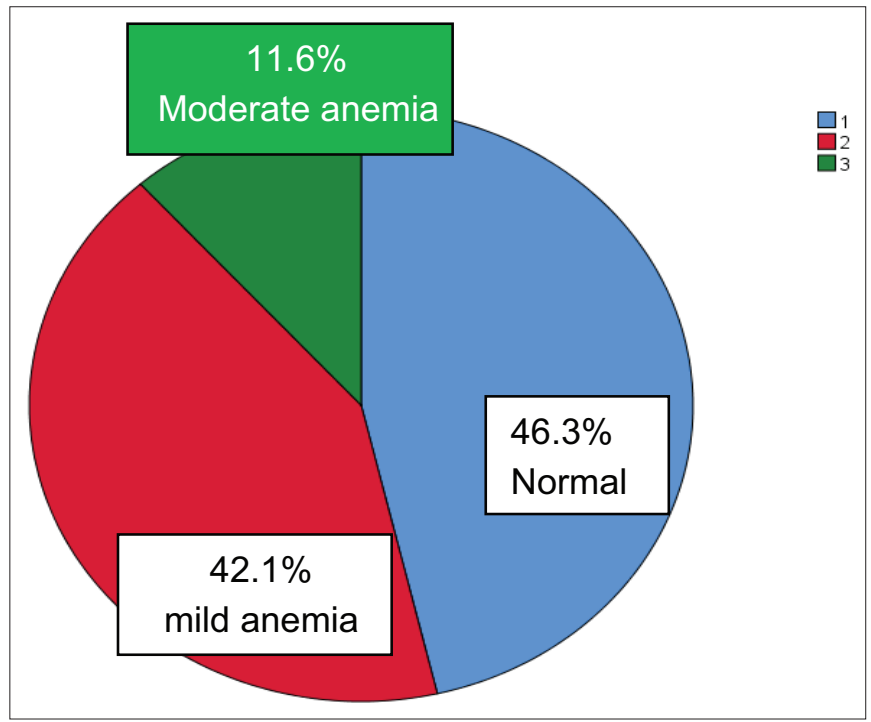

Figure 1: Frequency of Anemia in male medical students $(n=95)$

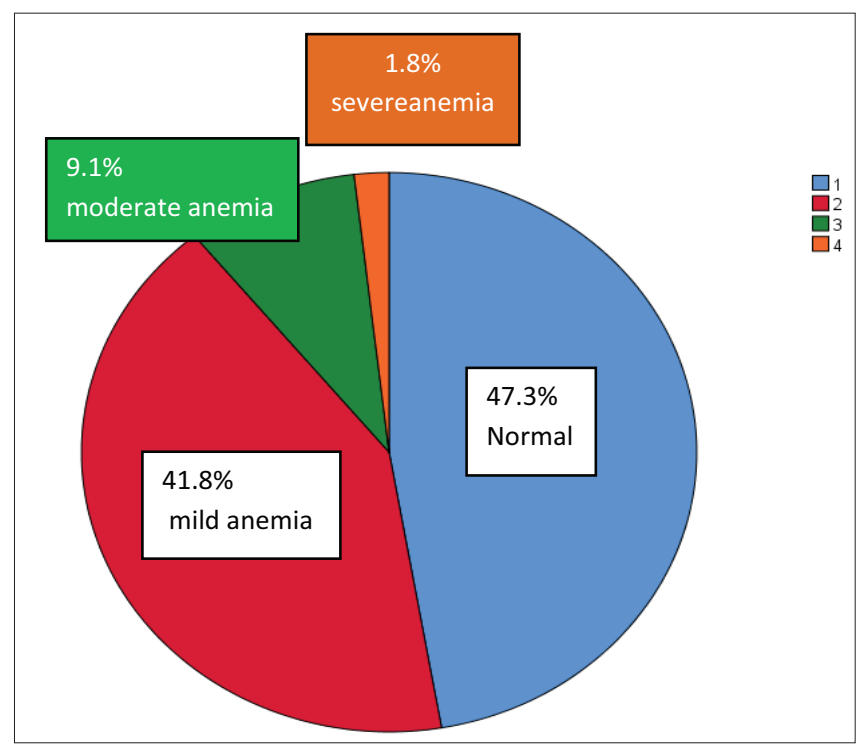

Figure 2: Frequency of Anemia in female medical students $(n=55)$

In a study by Jawed S, anemia was observed in $74(33.4 \%)$ students out of total 221 MBBS students. 57(25.8\%) students were having mild anemia $(\mathrm{Hb} \% 10.0-11.9 \mathrm{gm} / \mathrm{dl})$, $16(7.2 \%)$ had moderate anemia $(7-9.9 \mathrm{gmdl})$ and only $0.5 \%$ were severely anemic $(\leq 7 \mathrm{gm} / \mathrm{dl}) .{ }^{16}$ Both the result showed a common finding that the percentage of severely anemic was less than $2 \%$. Our study also reported the high percentage of mild anemia compared to moderate and severe anemia.

Saydam $\mathrm{BK}^{17}$ estimated the prevalence of anemia among reproductive age group of women from Turkey to be $27.8 \%$, out of it $6.9 \%$ were severely anemic. Comparing the prevalence with present study the severely anemic group was less compared to mild and moderately anemic. 
A study observed anemia in $29.07 \%$ of students out of which prevalence of anemia was significantly higher among female $(41.92 \%)$ than male $(11.64 \%)$ as analyzed by Agarwal AK et al..$^{18}$ Our study showed no variation in prevalence of anemia among male and female medical students. Both the group was found to be similar prevalence $53.7 \%$ in male and $51.7 \%$ in female. Though the percentage prevalence was found to be less, the anemia was more extensive in female participants in present study.

Our study recorded the correlation of 150 male and female medical students for hemoglobin and BMI which was negatively correlated $(\mathrm{r}=-0.112, \mathrm{p}=0.171)$ but not significant. The study done in Kathmandu Medical College by Gita Khakurel, ${ }^{19}$ there was a negative association of BMI to hemoglobin level among underweight girls and girls within normal BMI. But neither of the correlation showed significance considering the $\mathrm{p}<0.05$.

\section{CONCLUSION}

It has been concluded from the above study that the mild anemia is highly prevalent among medical students regardless of gender. Though the students are not severely affected, it is a subject of concern since the cause might be a negligence of food habit or the food facilities available at hostels. Further research is needed with a complete dietary habit of the individuals to get a complete analysis of causes for potential risk of anemia among students of hostels.

\section{LIMITATIONS}

This study needs a further evaluation with dietary habit of the participants and analyzing the morphology of red blood cells to know the type of anemia that is most common among medical students.

\section{ACKNOWLEDGEMENT}

I would like to acknowledge my participants for their voluntary involvement in the study and special thanks to the technician Mr.Manoj Rajbanshi for his great assistance during the sample collection.

\section{REFERENCES}

1. World Health Organization. Results and discussion. In: B de Benoist, E Mclean, I Egli, M Cogswell (eds). Worldwide Prevalence of Anemia 1993-2005: WHO Global Database on Anemia. WHO: Geneva, Switzerland, 2008; 1-51.

2. Thankachan P, Muthayya S, Walczyk T, Kurpad AV and Hurrell RF. An analysis of the etiology of anemia and iron deficiency in young women of low socioeconomic status in Bangalore, India. Food Nutr Bull 2007; 28: 328-336.

https://doi.org/10.1177/156482650702800309

3. Lal S, Pankaj A, Editors. Textbook of Community Medicine (Preventive and Social Medicine). $1^{\text {st }}$ ed. New Delhi: CBS Publishers and Distributors; 2007: 166-168.

4. Vivek RG, Halappanavar AB, Vivek PR, Halki SB, Maled VS and Deshpande PS. Prevalence of anemia and its epidemiological. Deter Pregnant Women 2012;5(3):216-223.

5. Basturk A, Kutlucan L, Kutlucan A, Pekin AT, Akinci S, Dagli M, et al. Evaluation of pregnant women awareness about anemia and factors affecting the development of anemia. Eur $\mathrm{J}$ Health Sci 2016;2(1):1-4.

https://doi.org/10.5505/eurjhs.2016.46855

6. Massawe SN, Urassa EN, Nyström L and Lindmark G. Anaemia in women of reproductive agein Dar-es-Salaam, Tanzania. East Afr Med J 2002;79(9):461-466.

https://doi.org/10.4314/eamj.v79i9.9117

7. Erdem O, Bucaktepe EG and Kara IH. Family medicine clinic women attending the iron deficiency anemia and gestation story relations. J Dicle Med 2009; 36:123-126.

8. Karakus V, Giden A, Ersil SD, Bozkurt S and Kurtoglu E. Evaluation of anemia in terms of etiology, risk factors, and relapse in adult patients. Mugla Med J 2016; 3:1-6.

9. Pandey $S$ and Singh A. A cross sectional study of nutritional Anemia among medical students in a medical college, at Bilaspur, Chhattisgarh. Natl J Med Res 2013;3:143-146.

10. Koushik NK, Bollu M and Ramarao NV. Prevalence of Anemia Among Adolescent Girls: A Three Months Cross-Sectional Study. World J Pharmacy 2014;3(12):827-836.

11. World Health Organization. Global nutrition targets 2025: Anemia policy brief. (WHO/NMH/NHD/14.4). Geneva: 2014; 1-5

12. Shams S, Asheri $H$, Kianmehr A, Ziaee V, Koochakzadeh L, Monajemzadeh $\mathrm{M}$, et al. The prevalence of iron deficiency anemia in female medical students in Tehran. Singapore Med J 2010; 51:116.

13. Balarajan $\mathrm{Y}$, Ramakrishnan U, Ozaltin E, Shankar AH and Subramanian SV. Anemia in low-income and middle-income countries. Lancet 2011; 378(9809):2123-2135.

14. Salhan S, Tripathi V, Singh R and Gaikwad HS. Evaluation of hematological parameters in partial exchange and packed cell transfusion in treatment of severe anemia in pregnancy. Anemia 2012; 608-658.

https://doi.org/10.1155/2012/608658

15. WHO/IASO/IOTF. The Asia Pacific Perspective: Redefining Obesity and its treatment. Health Communications Australia Pvt. Ltd. 2000.1-56.

16. Jawed S, Tariq S, Tariq S and Kamal A. Frequency of nutritional anemia among female medical students of Faisalabad. Pak J Med Sci 2017;33(2):398-403.

https://doi.org/10.12669/pjms.332.11854

17. Saydam BK, Genc RE, Sarac F and Turfan EC. Prevalence of anemia and related factors among women in Turkey. Pak J Med Sci 2017; 33(2):433-438.

https://doi.org/10.12669/pjms.332.11771

18. Agarwal AK, Katiyar Das G, Mahmood SE, Khan S and Sharma M. A cross sectional study of association of anaemia with BMI in medical and paramedical students. Int J Community Med Public Health 2017; 4(12):4697-4701. https://doi.org/10.18203/2394-6040.ijcmph20175353

19. Khakurel G, Chalise S and Pandey N. Correlation of Hemoglobin Level with Body Mass Index in Undergraduate Medical Students. Indian Journal of Basic and Applied Medical Research 2017; 4 (6): 318-323. 
Authors Contribution:

RY- Concept and design of the study, manuscript preparation, statistically analyzed and interpreted, critical revision of the manuscript; SM- critical revision of manuscript and review of the study; NG- reviewed the literature; SKY-Collected data, statistically analyzed and interpreted the manuscript.

Work attributed to:

Department of Physiology, Nobel Medical College and Teaching Hospital, Biratnagar

Orcid ID:

Dr. Renu Yadav- (i) http://orcid.org/0000-0002-8126-6585

Dr. Soumitra Mukhopadhyay- (D) https://orcid.org/0000-0002-6442-4713

Dr. Nisha Ghimire- (1) http://orcid.org/0000-0001-9615-196X

Dr Subodh Kumar Yadav- (i) https://orcid.org/0000-0002-8482-5928

Source of Support: Nil, Conflicts of Interest: None declared. 